\title{
Pharmacokinetics and Pharmacodynamics of Moracizine (EN-313) in Healthy Japanese Volunteers
}

\author{
Hirotsugu ATARASHI* Takeshi INO* and \\ Hirokazu HAYAKAWA*
}

(Received on July 22, 1993)

\begin{abstract}
*First Department of Internal Medicine, Nippon Medical School, Tokyo, Japan 1-1-5 Sendagi, Bunkyo-ku, Tokyo 113, Japan
\end{abstract}

We administered single oral doses of $100,200,300$ and $400 \mathrm{mg}$ of EN-313 and repeated oral doses of $300 \mathrm{mg}$ t.i.d., for 1 and 7 days to healthy adult men to confirm the safety and pharmacokinetics of this agent and to elucidate the effect of meals on the pharmacokinetics at a dose of $300 \mathrm{mg}$. At single doses of 100 and $200 \mathrm{mg}$, there were subjective symptoms of dizziness and nausea, but these were slight, and were regarded to have no relation to the test agent. No objective symptom was observed. And there was no abnormal finding in blood pressure, pulse rate, body temperature, or the results of laboratory tests. There was no significant change in the ECG parameters or in the hemodynamic parameters obtained by echocardiogram. After oral administration, EN-313 was rapidly absorbed, and reached $\mathrm{C}_{\max }$ in $0.77 \sim 1.17 \mathrm{hrs}$. EN-313 disappeared in two phases, and its $\mathrm{T}_{1 / 2}$ was 2.21 to 3.08 hrs. EN-313 showed a linear increase in $\mathrm{C}_{\max }$ and AUC concomitant with the dose increase. The $\mathrm{T}_{\max }$ of $\mathrm{EN}-313$ was prolonged from 0.97 to $1.45 \mathrm{hrs}$ when administered after breakfast. The rates of excretion of the compounds in the urine were less than $1 \%$ (EN-313, $0.04 \%$; INX-5575, 0.51\%; INS-9673, 0.206\%), even at the dose of $400 \mathrm{mg}$.

In the repeat-dose study, subjective/objective symptom, blood pressure, body temperature and laboratory test data indicate no abnormal change considered to be caused by EN-313.

However, in the seven-day test, a significant increase in pulse rate was observed from day 4 of administration. ECGs revealed shortened RR on $\mathrm{QT}$ intervals and a prolonged PQ interval, but no significant change was observed QRS width or in QTc. No significant change was observed in hemodynamic parameters.

In the one-day test, the $\mathrm{T}_{\max }$ of $\mathrm{EN}-313$ after the first administration was $1.5 \mathrm{hrs}$ and the $\mathrm{C}_{\max }$ was $0.728 \mu \mathrm{g} / \mathrm{ml}$. After the second administration, $\mathrm{T}_{\max }$ doubled and $\mathrm{C}_{\max }$ was $0.482 \mu \mathrm{g} / \mathrm{ml}$. $\quad \mathrm{C}_{\max }$ after the third administration was lower than after the second. Twelve hrs after the third administration, the concentration of EN-313 was only approximately 0.05 $\mu \mathrm{g} / \mathrm{ml}$, with no drug accumulation.

And in the seven-day test, the $\mathrm{C}_{\max }$ of $\mathrm{EN}-313$ was $0.465 \mu \mathrm{g} / \mathrm{ml}$ on day 1 , and was at a similar level on day 4 , but on day 7 it was decreased to $0.288 \mu \mathrm{g} / \mathrm{ml}$. The AUC of EN313 was $1.48 \mu \mathrm{g} / \mathrm{ml}$ on day 1 and $1.519 \mu \mathrm{g} / \mathrm{ml}$ on day 4 , then on day 7 it fell to $0.893 \mu \mathrm{g} / \mathrm{ml}$, but the difference between the day 1 and 7 values was not statistically significant. $T_{\max }$ for EN-313 were $3.17,1.83$ and $3.67 \mathrm{hrs}$ on days 1,4 and 7 , respectively. No accumulation of EN-313 was seen throughout the 7-day oral administration. The total excreted amount of EN-313, INX-5575 and INX-9673 was less than 1\%.

The above results demonstrate the safety of $\mathrm{EN}-313$ for clinical use; no problems have arisen during a 7-day period of multiple-dose administration.

* 日本医科大学附属病院第一内科 $\overline{\mathrm{T}} 113$ 東京都文京区千駄木 1-1-5 
Key words: moracizine, single oral dose, repeat-dose study, healthy volunteer, pharmacokinetics

\section{Introduction}

Moracizine (EN-313) (Moracizine: USAN, Ethmozine ${ }^{\circledR}$ by Du Pont), or 10-(3-morpholinopropionyl) phenothiazine-2-carbamic acid ethyl ester hydrochloride, is an oral antiarrhythmic agent that was synthesized by the Academy of Medical Science of the USSR in 1964 (Fig. 1). Since 1976, the development of this agent has been continued by Du Pont in the USA. The agent was approved by the Food and Drug Administration of the USA in 1990.

The metabolism of EN-313 has been studied in humans, rats and dogs; the sulfur in the main phenothiazine chain is oxidized, and the side chains at the 2-position $\left(-\mathrm{NH}-\mathrm{COOC}_{2} \mathrm{H}_{5}\right)$ and the 10 -position $\left(-\mathrm{COC}_{2} \mathrm{H}_{4}-\mathrm{NO}\right)$ are dealkylated and hydroxidized. The agent is further metabolized when it is subjected to conjugation with glucuronic acid. In humans, 26 metabolites have been confirmed and 14 of these have been identified.

Electrophysiologic studies in animals have shown that $\mathrm{EN}-313$ inhibits the phase 0 inward $\mathrm{Na}$ current in Purkinje fibers, reduces the maximum depolarization velocity $\left(\mathrm{V}_{\max }\right)^{1)}$, and has a local anesthetizing action and membrane stabilizing activity. Thus, EN-313 is regarded to belong to Class I of the Vaughan Williams classification. It was reported clinically that EN-313 prolongs both the $\mathrm{AH}$ and $\mathrm{HV}$ intervals $^{2 \sim 4)}$. Electrocardiography shows that this agent prolongs the $\mathrm{PR}$ and $\mathrm{QRS}$ intervals ${ }^{3 \sim 5)}$. Some comparative clinical studies conducted outside Japan which focussed on ventricular premature beats and non-sustained ventricular tachycardia, revealed that $\mathrm{EN}-313$ is as effective as quinidine $\mathrm{e}^{5,6}$, and it is more effective than propranolol and disopyramide ${ }^{7,8)}$.

In the present phase I studies of $\mathrm{EN}-313$ conducted in Japan, single oral doses and repeat oral doses of $300 \mathrm{mg}$, t.i.d. for one and seven

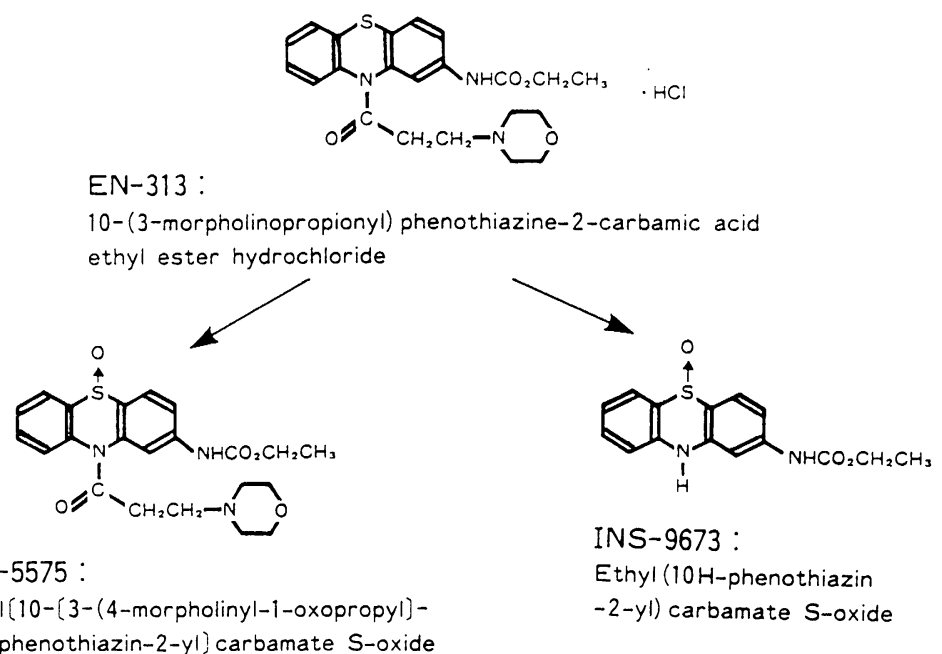

Fig. 1 Chemical structures of $\mathrm{EN}-313$ and its metabolites 
days were administered to healthy adult male volunteers to confirm the safety and pharmacokinetics of this agent. We also studied the effect of meals on the pharmacokinetics at a dose of $300 \mathrm{mg}$.

\section{Subjects and Methods}

\section{Institution}

This study was performed from July 1990 to October 1991 at the Housen Clinic in Tokyo, and this study was approved by the Institutional Review Board, of the Clinic.

\section{Selection and Care of Subjects}

Sixteen healthy men (age 21.9 $\pm 0.5 \mathrm{yrs}$, body weight $62.9 \pm 1.8 \mathrm{~kg}$ ) for the single-dose tests, 6 men (age $22.3 \pm 0.5 \mathrm{yrs}$, body weight $63.2 \pm$ $3.9 \mathrm{~kg}$ ) for the test examining the effect of

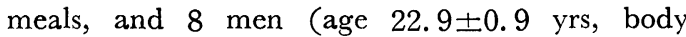
weight $69.8 \pm 3.6 \mathrm{~kg}$ ) for the 4 steps of the pharmacokinetic tests were enrolled in this study series. In the repeated dose study, 6 men (age $21.5 \pm 0.8$ yrs, body weight $64.0 \pm 3.4 \mathrm{~kg}$ ) were included in the one-day test, and 6 men (age $23.0 \pm 0.8$ yrs, body weight $60.2 \pm 1.8 \mathrm{~kg}$ ) in the seven-day test.

Before the study began, the subjects were given an explanation by the physician in charge in conformity with the GCP, all subjects gave informed consent to participate in the study.

The subjects were admitted to the clinic by dinner time on the day before the study, and remained until 9:00 a.m. on the day after all the tests were completed. During this period, they were placed under the control of the physicians. They were given designated meals and water or barley tea during their hospitalization, and they were not allowed to have alcoholic or caffeine-containing beverages.

\section{Doses and Method of Administration}

The initial dose for humans (assuming a body weight of $60 \mathrm{~kg}$ ) was set at $1 / 60$ of the noeffect dose obtained in a 3-month administration test in rats, therefore an initial dose of $20 \mathrm{mg} /$ day for all assuming $60 \mathrm{~kg}$ body weight was originally selected. However, in a single-dose test ${ }^{9)}$ already conducted in the US on healthy subjects and using a dose range of $50 \sim 1,225$ $\mathrm{mg}$, there was no adverse reaction with single doses of 50,75 , and $100 \mathrm{mg}$, or with multiple doses of the same levels given three times a day for 7 days. Furthermore, the safety of EN-313 has been confirmed in the clinical dose range of $200 \mathrm{mg}$ to $300 \mathrm{mg}$ given three times a day6,7, 10,11, ). In view of the above, and taking racial differences into consideration, we started with an initial dose of $100 \mathrm{mg}$ for Japanese subjects. Single-dose studies were conducted at 100, 200, 300 and $400 \mathrm{mg}$. For each dose, 6 subjects were given the active agent,and 2 subjects received a placebo in a single-blind manner. The same subjects were employed for $100 \mathrm{mg}$ and $300 \mathrm{mg}$ also $200 \mathrm{mg}$ and $400 \mathrm{mg}$.

For the test examining the effect of meals, the 6 subjects were divided into two groups of 3 men each. In one group, the test drug was administered after breakfast (sandwich, yogurt and soup; $395 \mathrm{Cal}$ ), and in the other, it was given with no breakfast. The subjects were tested in a cross-over method using a singledose of $300 \mathrm{mg}$, with a week's washout period before examination with the next test. Each dose of the pharmacokinetic tests was conducted on two men by Latin square randomization, and the same dose of the test drug was administered as in the single-dose tests. The steps were separated by intervals of four weeks.

In consideration of the effects of the singledose study, the dose of the repeat-dose study was set at $300 \mathrm{mg}$ given three times a day (900 
$\mathrm{mg} /$ day), on the basis of the clinical dosage used in the US. After the safety of the one-day test was confirmed, the seven-day administration test was started.

\section{Test Agents}

Film-coated tablets containing 50, 100, or $200 \mathrm{mg}$ of EN-313 were used as the test drug. The placebo used in the study were film-coated tablets contained no EN-313 and were mainly composed of lactose. At each step, the test dose was 2 tablets, and these were taken with $100 \mathrm{ml}$ of water.

\section{Clinical Observation}

The following evaluations were made,

a) Physician's interview, physical examination and subjective symptoms were checked periodically after the administration until the tests were complete.

b) Blood pressure and pulse rate

c) Body temperature

d) Electrocardiography (Standard 12-leads ECG and ECG monitoring)

e) Echocardiography

LV end-diastolic and end-systolic dimensions were measured (Toshiba SSA-250 A ultrasound scanner) in the single-dose study and in the seven-day test.

f) Laboratory tests

Hematological tests, blood chemistry tests, and urine tests were performed.

\section{Pharmacokinetics}

The plasma and urine concentrations of unaltered EN-313 and its metabolites, INX5575 and INS-9673, were determined (Fig. 1). INX-5575 and INS-9673 are metabolites common to humans and rats. It has been previously confirmed in an aconitine-induced ventricular arrhythmia model in rats that INX-5575 has the same level of activity as EN-313 and that INS-9673 has about one-third of the activity of $\mathrm{EN}-313^{9)}$.

In the single-dose study, venous blood sampling was carried out before administration, and at 20, $40 \mathrm{~min}$, and $1,1.5,2,3,4,6,8,12$, and $24 \mathrm{hrs}$ after administration. Urine samples were taken and stored before, and during the periods $0 \sim 4,4 \sim 8,8 \sim 12$, and $12 \sim 24$ hrs after, administration. In the repeat-dose study, venous blood was sampled a total of 12 times for the one-day test, and a total of 30 times for the seven-day test. Urine samples were collected in 4 and 14 periods, respectively. Blood samples ( $9 \mathrm{ml}$ each) were taken from an antecubital vein into heparin-containing tubes under shielded conditions. Samples were immediately centrifuged to obtain $3 \mathrm{ml}$ each of plasma, and the plasma was stored below $-20^{\circ} \mathrm{C}$ until the time of analysis Urine samples collected during each period were combined and weighed, and then a $50 \mathrm{ml}$ sample was taken for each period and stored below $-20^{\circ} \mathrm{C}$ until the time of analysis.

\section{Measurements of Plasma and Urine Levels of EN-313 and Metabolites}

The concentrations of EN-313 and its metabolites in plasma and urine were determined by high pressure liquid chromatography. (HPLC) (LC-6 A, Shimadzu Corp., Kyoto, Japan) using reversed phase columns according to a modification of the method of Whitney et al.12)

\section{Pharmacokinetic Analysis}

The pharmacokinetic behavior of EN-313 was analyzed from the measured values rather than from a model. The highest measured concentration in the plasma was defined as the maximum concentration in plasma $\left(\mathrm{C}_{\max }\right)$. The time required to each this concentration in plasma was termed as $T_{\max }$. The biological half-life, $T_{1 / 2}$, 
was obtained by the least squares method from the elimination phase (the $\beta$ phase in the case of $\mathrm{EN}-313)$ in the plasma. The area under the concentration curve, AUC, was obtained from the trapezoidal formula up to $24 \mathrm{hrs}$ after administration in the single-dose test; up to 6 hrs after the first and second administration in the one-day test; and up to $6 \mathrm{hrs}$ after the morning administration on days 1,4 , and 7 in the seven-day test.

\section{Statistical Analysis}

All values in this report are given as means $\pm \mathrm{SE}$. The blood pressure, pulse rate, body temperature, ECG parameters, the hemodynamic data obtained by echocardiography, and pharmacokinetic parameter were analyzed by using Student's paired t-test. Pharmacokinetic parameters on the test of the effect of meals were assessed by ANOVA. $\mathrm{C}_{\max }$-dose and AUC-dose correlations were calculated using linear regression analysis. $p<0.05$ was regarded to be of statistical significance.

\section{Results}

\section{Subjective and Objective Symptoms}

Single-dose study: One subject who had taken $100 \mathrm{mg}$ of EN-313 complained of slight discomfort (dizziness and nausea) at the time of blood sampling $6 \mathrm{hrs}$ after the administration of the test agent, but after the subject rested in bed, the symptoms disappeared spontaneously. When the symptom appeared, no significant decrease in blood pressure was observed, and the period during which it appeared suggested that it was not caused by the test agent. In the single dose of $200 \mathrm{mg}$ group, a subject complained of slight sleepiness $1 \mathrm{hr}$ after the administration of the drug. This symptom disappeared after $1 \mathrm{hr}$. In another subject who had taken $200 \mathrm{mg}$, the subject reported general malaise and felt feverish and heavy-headed $10 \mathrm{~min}$ after drug administration. The malaise disappeared after $1.5 \mathrm{hrs}$, and the other symptoms after $4 \mathrm{hrs}$. The subjective symptoms in both of these two cases were slight and of unknown cause.

No subjective symptoms were reported in the $300 \mathrm{mg}$ and $400 \mathrm{mg}$ tests or in the test of effect of meals.

Repeat-dose study: In the one-day test, one subject complained of slight temporary headache $1 \mathrm{hr}$ after the second administration. However, this subject reported typically having this symptom fairly frequently in his daily life, and so the symptom was considered to be unrelated to the administration of the test agent. Another subject complained of temporary dizziness $5 \mathrm{hrs}$ after the second administration without change in blood pressure, but the symptom quickly disappeared, and thus was thought to be unrelated to the test agent. And in the seven-day test, no subjective/ objective symptom was observed throughout the test.

There were no abnormal findings in the physical examinations in all tests.

\section{Blood Pressure and Pulse Rate}

Single-dose study: EN-313 had no significant effect on the blood pressure. A decrease in the pulse rate from $20 \mathrm{~min}$ to $2 \mathrm{hrs}$ after administration was observed in the single-dose tests at 100,200 and $300 \mathrm{mg}$, but the same change was also found in the placebo group.

Repeat-dose study: In the one-day test, there were no significant changes in blood pressure or pulse rate during the study. And in the sevenday test, there was a slight reduction in the diastolic pressure $1 \mathrm{hr}$ after the morning administration on day 1 , and a slight increase in the systolic pressure $24 \mathrm{hrs}$ after the morning administration on day 7. However, no significant change in blood pressure was observed at any 

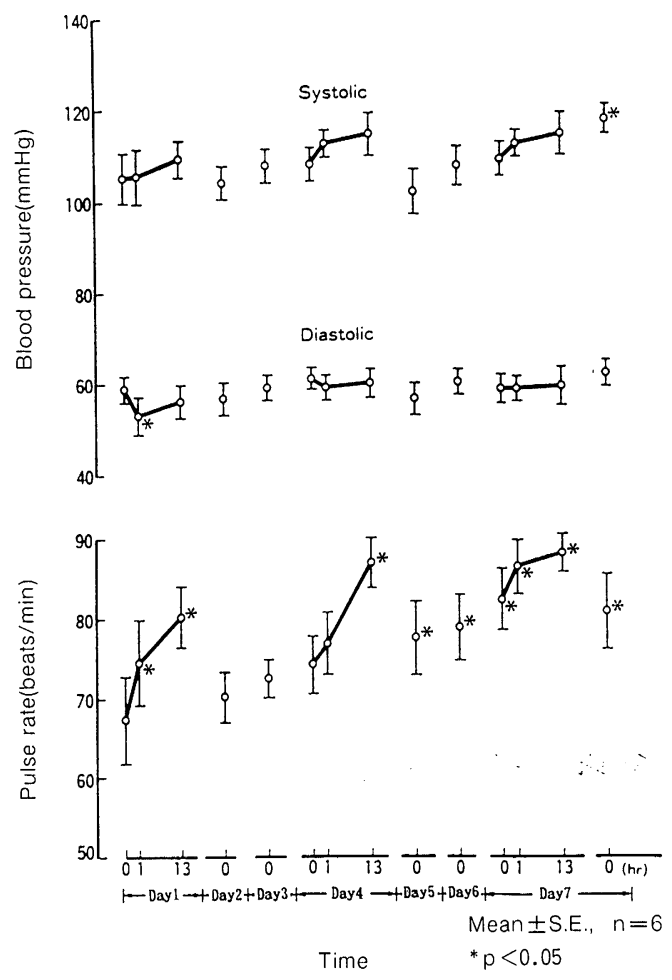

Fig. 2 Blood pressure and pulse rate in the seven-day test

time during this study. A significant increase in pulse rate was observed on day 4 and persisted until $24 \mathrm{hrs}$ after the morning administration on day 7 (Fig. 2).

\section{Body Temperature}

Single-dose study: There was no abnormal change in the body temperature.

Repeat-dose study: In the one-day test, the temperatures taken $1 \mathrm{hr}$ after the second and third administrations were higher than the levels prior to the initial administration in the morning. They returned to normal levels the next morning. These changes were considered to be diurnal changes. And in the seven-day test, no abnormal temperature change was observed during the period of hospitalization.

\section{Laboratory Tests}

In the single-dose study and one-day test, there was a minor change in the leucocyte fraction, but no significant change was observed in its percentage after administration compared with that before. And in the seven-day test, no abnormal finding attributable to the test agent was observed.

\section{Electrocardiogram}

Single-dose study: An appreciable reduction in the RR interval was observed at the doses of $200 \mathrm{mg}$ and $400 \mathrm{mg}$ between $200 \mathrm{~min}$ and 4 hrs after drug administration. Eight and $12 \mathrm{hrs}$ after administration, the $R R$ interval became short in all the groups, including the placebo group. A significant increase in the $\mathrm{PQ}$ interval was found only in the dose group of $300 \mathrm{mg}$ at 1.5 and $4 \mathrm{hrs}$ after administration. There was no significant change in the QRS width or in QTc, nor was there any change in the ST. T or $\mathrm{U}$ wave morphology (Fig. 3 ).

Repeat-dose study: In the one-day test, there was no significant change in $R R$ or $P Q$ intervals, QRS width, or QTc, and also no abnormal change in the ST.T or in $\mathrm{U}$ wave morphology during the study.

In the seven-day test, one case of first degree atrioventricular block was recorded before the morning administration on day 4; the PQ prolongation persisted until $1 \mathrm{hr}$ after administration of the same day. Shortened RR intervals were observed on days, 1,4 and 7 , compared with the control value prior to administration on day 1. As the RR interval became shorter, the QT interval was reduced on days, 1, 4 and 7, and the $P Q$ interval became longer from after the morning administration on day 4 until the final measurement on day 7. There was no significant change in any other parameter ( $Q R S$ width, QTc, ST. $\mathrm{T}$ and U wave) (Fig. 4). 

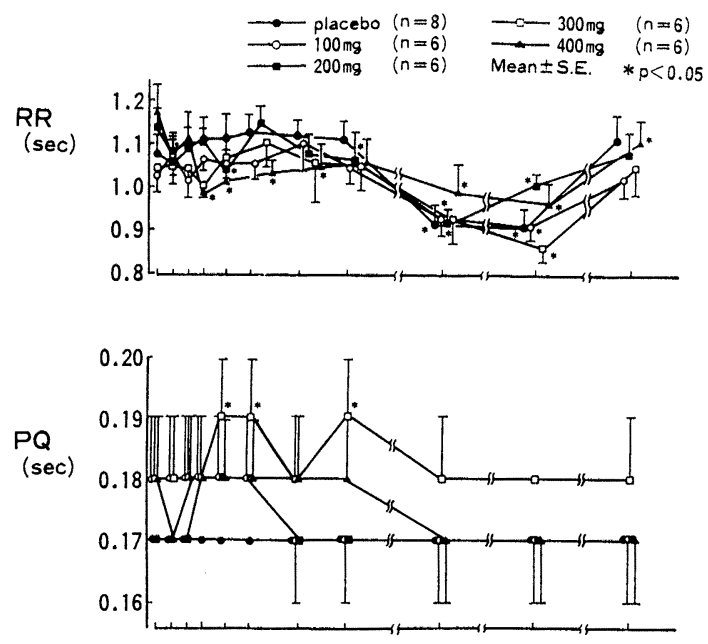

QRS
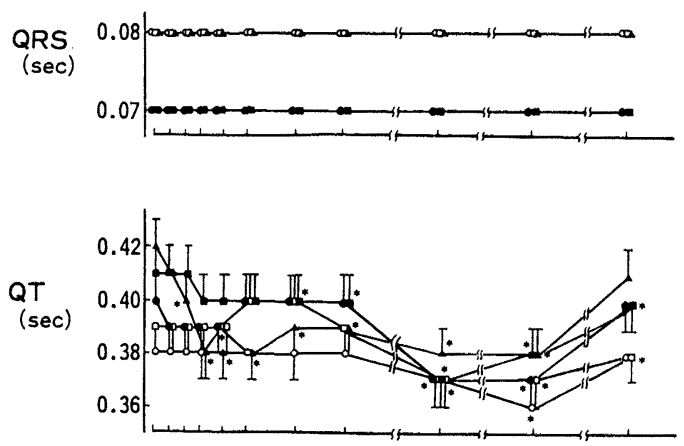

QTc

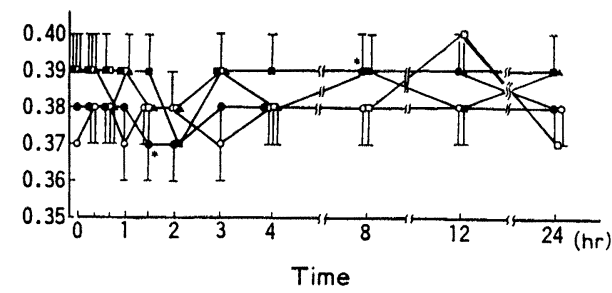

Fig. 3 Electrocardiographic parameters after different single oral doses of $\mathrm{EN}-313$

\section{Echocardiograms}

Single-dose study: No abnormal change associated with EN-313 was observed, except that LVEDS, LVEDD and related parameters increased minimally with the dose of $200 \mathrm{mg}$ (Tab. .)

Seven-day test: EN-313 had no obvious effect

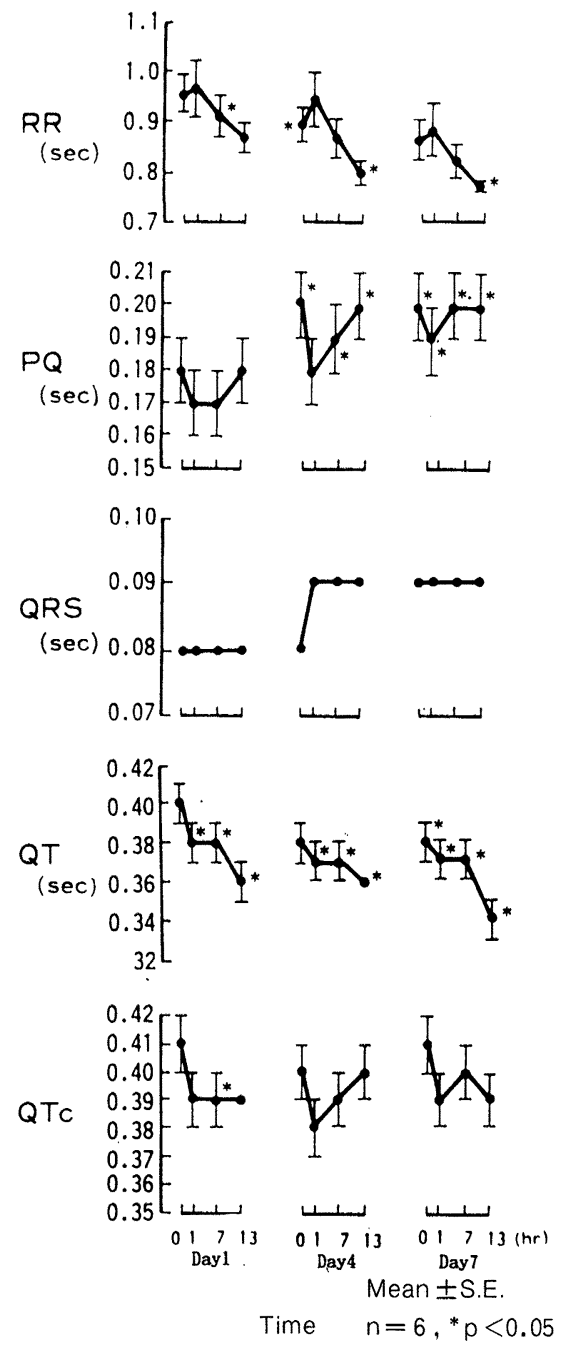

Fig. 4 Electrocardiographic parameters in the seven-day test

on the echocardiographic data (Tab. 2).

\section{Pharmacokinetics}

Single-dose study: After oral administration, EN-313 was quickly absorbed, and reached $\mathrm{C}_{\max }$ in $0.77 \sim 1.17 \mathrm{hrs}\left(\mathrm{T}_{\max }: 0.95 \mathrm{hr}\right.$ on an average, $\mathrm{N}=32$ ). $\mathrm{EN}-313$ disappeared in two phases, and its $T_{1 / 2}$ was 2.21 to $3.08 \mathrm{hrs}$. It had almost disappeared from the plasma by $24 \mathrm{hrs}$ after admin- 
Tab. 1 Hemodynamic Parameters in the Single-Dose Study

\begin{tabular}{c|c|c|c|c|c|c|c|c}
\hline Dose & $\begin{array}{c}\text { Time } \\
(\mathrm{hr})\end{array}$ & $\begin{array}{c}\text { LVEDD } \\
(\mathrm{mm})\end{array}$ & $\begin{array}{c}\text { LVEDV } \\
(\mathrm{ml})\end{array}$ & $\begin{array}{c}\text { LVESD } \\
(\mathrm{mm})\end{array}$ & $\begin{array}{c}\text { LVESV } \\
(\mathrm{ml})\end{array}$ & $\begin{array}{c}\text { SV } \\
(\mathrm{ml})\end{array}$ & $\begin{array}{c}\text { EF } \\
(\%)\end{array}$ & $\begin{array}{c}\text { FS } \\
(\%)\end{array}$ \\
\hline \multirow{2}{*}{ Placebo } & 0 & $50 \pm 1$ & $133.4 \pm 5.9$ & $33 \pm 1$ & $38.9 \pm 2.9$ & $94.5 \pm 3.3$ & $71.0 \pm 1.0$ & $33.9 \pm 0.7$ \\
& 1.5 & $50 \pm 1$ & $133.3 \pm 5.4$ & $33 \pm 1$ & $38.7 \pm 2.3$ & $94.6 \pm 3.5$ & $71.0 \pm 0.9$ & $33.9 \pm 0.6$ \\
\hline \multirow{2}{*}{$100 \mathrm{mg}$} & 0 & $50 \pm 1$ & $128.8 \pm 6.9$ & $33 \pm 1$ & $36.8 \pm 4.2$ & $92.1 \pm 3.7$ & $71.9 \pm 2.1$ & $34.7 \pm 1.7$ \\
& 1.5 & $49 \pm 1$ & $125.2 \pm 7.8$ & $32 \pm 1$ & $35.3 \pm 4.4$ & $89.9 \pm 4.1$ & $72.3 \pm 2.1$ & $34.8 \pm 1.7$ \\
\hline \multirow{2}{*}{$200 \mathrm{mg}$} & 0 & $48 \pm 1$ & $113.8 \pm 5.6$ & $31 \pm 1$ & $32.2 \pm 3.1$ & $81.6 \pm 3.4$ & $71.9 \pm 1.8$ & $34.7 \pm 1.4$ \\
& 1.5 & $48 \pm 1^{*}$ & $118.8 \pm 6.4 *$ & $32 \pm 1^{*}$ & $35.4 \pm 3.3 *$ & $83.3 \pm 3.8$ & $70.4 \pm 1.8 *$ & $33.5 \pm 1.4$ \\
\hline \multirow{2}{*}{$300 \mathrm{mg}$} & 0 & $49 \pm 1$ & $121.3 \pm 6.6$ & $32 \pm 1$ & $34.0 \pm 3.8$ & $87.3 \pm 3.7$ & $72.4 \pm 1.9$ & $34.8 \pm 1.5$ \\
& 1.5 & $49 \pm 1$ & $124.0 \pm 7.9$ & $32 \pm 1$ & $35.7 \pm 4.2$ & $88.3 \pm 4.9$ & $71.6 \pm 2.1$ & $34.5 \pm 1.6$ \\
\hline \multirow{2}{*}{$400 \mathrm{mg}$} & 0 & $49 \pm 1$ & $119.9 \pm 5.9$ & $33 \pm 1$ & $36.3 \pm 2.7$ & $83.6 \pm 4.2$ & $69.8 \pm 1.6$ & $33.0 \pm 1.2$ \\
& 1.5 & $48 \pm 1$ & $118.8 \pm 6.4$ & $33 \pm 1$ & $36.9 \pm 2.8$ & $81.9 \pm 4.4$ & $69.1 \pm 1.4$ & $32.5 \pm 1.0$ \\
\hline
\end{tabular}

Mean \pm S.E., ${ }^{*} \mathrm{p}<0.05$ (Versus values before administration), $\mathrm{n}=6$ (Placebo $\mathrm{n}=8$ )

Tab. 2 Hemodynamic Parameters in the Seven-Day Test

\begin{tabular}{l|c|c}
\hline & $\begin{array}{c}\text { Before } \\
\text { administration }\end{array}$ & $\begin{array}{l}\text { 1 hour after the } \\
\text { last administ- } \\
\text { ration }\end{array}$ \\
\hline LVEDD (mm) & $46 \pm 1$ & $46 \pm 1$ \\
LVEDV (ml) & $104.9 \pm 6.8$ & $104.6 \pm 5.2$ \\
LVESD (mm) & $28 \pm 0$ & $28 \pm 0$ \\
LVESV (ml) & $22.6 \pm 1.0$ & $22.6 \pm 0.8$ \\
SV (ml) & $82.2 \pm 6.1$ & $81.9 \pm 4.6$ \\
EF (\%) & $78.2 \pm 1.0$ & $78.2 \pm 0.7$ \\
FS (\%) & $39.9 \pm 0.9$ & $39.9 \pm 0.7$ \\
\hline
\end{tabular}

Mean \pm S.E., $n=6$

istration (Fig. 5 and Tab. 3). EN-313 showed a linear pharmacokinetic behavior, $\mathrm{C}_{\max }$ and AUC increased dose-dependently (Fig. 6).

The $\mathrm{T}_{\max }$ of INX-5575 was $1.02 \sim 1.23 \mathrm{hrs}$ (mean $1.15 \mathrm{hrs} ; \mathrm{N}=32$ ). This metabolite disappeared in one phase, its $\mathrm{T}_{1 / 2}$ being $2.03 \sim 2.69$ hrs. INX-5575 was not detected in the plasma $24 \mathrm{hrs}$ after administration. The $\mathrm{C}_{\max }$ was about $2 / 5$ to $1 / 4$ of that of $\mathrm{EN}-313$ and the AUC was about $1 / 2$ to $1 / 3$ of that of $E N-313$.

INS-9673 had a $T_{\max }$ of $1.44 \sim 1.83 \mathrm{hrs}$ (mean $1.6 \mathrm{hrs} ; \mathrm{N}=32$ ) and a $\mathrm{T}_{1 / 2}$ of $3.90 \sim 4.24 \mathrm{hrs}$.
Its $\mathrm{C}_{\max }$ was about $1 / 20$ of that of $\mathrm{EN}-313$, and its AUC, about $1 / 10$ of that of EN-313.

In the effect of meal test, the $\mathrm{T}_{\max }$ of $\mathrm{EN}$ 313 was compared between the fasting group and the group that had breakfast, revealing a prolongation from $0.97 \mathrm{hr}$ to $1.45 \mathrm{hrs}$ in the latter group. But this prolongation was not significant on statistical analysis. No significant difference was observed in any other pharmacokinetic parameter (Fig. 7).

Repeat-dose study: In the one-day test, the $\mathrm{T}_{\max }$ of $\mathrm{EN}-313$ after the first administration was $1.5 \mathrm{hrs}$ and the $\mathrm{C}_{\max }$ was $0.728 \mu \mathrm{g} / \mathrm{ml}$. After the second administration, $\mathrm{T}_{\max }$ doubled and $\mathrm{C}_{\max }$ was $0.482 \mu \mathrm{g} / \mathrm{ml} . \mathrm{C}_{\max }$ after the third administration was lower than that after the second, though the time over which the measurements were made differed. Twelve hrs after the third administration, the concentration of EN-313 was only approximately $0.05 \mu \mathrm{g} / \mathrm{ml}$, with no drug accumulation. The plasma concentration of INX-5575 was about $1 / 3$ that of EN-313, and it varied in a manner similar to EN-313. The level of INS-9673 was far lower (Fig. 8, Tab. 4). 
Tab. 3 Pharmacokinetic Parameters of EN-313, INX-5575 and INS-9673 after Various Single Oral Doses of EN313

\begin{tabular}{c|l|l|l|l}
\hline Dose (Step) & & EN-313 & INX-5575 & INS-9673 \\
\hline \multirow{3}{*}{$100 \mathrm{mg}$} & $\mathrm{AUC}$ & $0.513 \pm 0.182$ & $0.293 \pm 0.061$ & $0.059 \pm 0.012$ \\
(Step II-1) & $\mathrm{C}_{\max }$ & $0.254 \pm 0.078$ & $0.098 \pm 0.016$ & $0.011 \pm 0.001$ \\
& $\mathrm{~T}_{\max }$ & $1.17 \pm 0.31$ & $1.21 \pm 0.30$ & $1.52 \pm 0.38$ \\
& $\mathrm{~T}_{1 / 2}$ & $2.21 \pm 0.35$ & $2.69 \pm 0.53$ & $3.90 \pm 0.39$ \\
\hline \multirow{2}{*}{$200 \mathrm{mg}$} & $\mathrm{AUC}$ & $1.470 \pm 0.410$ & $0.604 \pm 0.121$ & $0.143 \pm 0.024$ \\
(Step II-2) & $\mathrm{C}_{\max }$ & $0.695 \pm 0.182$ & $0.174 \pm 0.029$ & $0.021 \pm 0.003$ \\
& $\mathrm{~T}_{\max }$ & $0.82 \pm 0.11$ & $1.19 \pm 0.28$ & $4.24 \pm 0.33$ \\
& $\mathrm{~T}_{1 / 2}$ & $2.28 \pm 0.24$ & $2.03 \pm 0.21$ & $0.200 \pm 0.030$ \\
$300 \mathrm{mg}$ & $\mathrm{AUC}$ & $2.467 \pm 0.489$ & $0.936 \pm 0.136$ & $0.028 \pm 0.004$ \\
(Step II-3) & $\mathrm{C}_{\max }$ & $1.129 \pm 0.215$ & $0.257 \pm 0.035$ & $1.44 \pm 0.15$ \\
& $\mathrm{~T}_{\max }$ & $0.77 \pm 0.10$ & $1.02 \pm 0.17$ & $4.17 \pm 0.23$ \\
\hline & $\mathrm{T}_{1 / 2}$ & $2.68 \pm 0.09$ & $2.35 \pm 0.23$ & $0.305 \pm 0.045$ \\
400 mg & $\mathrm{AUC}$ & $3.534 \pm 0.654$ & $1.357 \pm 0.191$ & $0.040 \pm 0.006$ \\
(Step II-4) & $\mathrm{C}_{\max }$ & $1.412 \pm 0.284$ & $0.318 \pm 0.038$ & $1.83 \pm 0.40$ \\
& $\mathrm{~T}_{\max }$ & $1.06 \pm 0.14$ & $1.23 \pm 0.19$ & $4.17 \pm 0.23$ \\
\hline
\end{tabular}

AUC $(0 \sim 24): \mu \mathrm{g} \cdot \mathrm{hr} / \mathrm{ml}, \quad \mathrm{C}_{\max }: \mu \mathrm{g} / \mathrm{ml}, \mathrm{T}_{\max }: \mathrm{hr}, \mathrm{T}_{1 / 2}: \mathrm{hr}, \quad$ Mean \pm S.E., $\mathrm{n}=8$
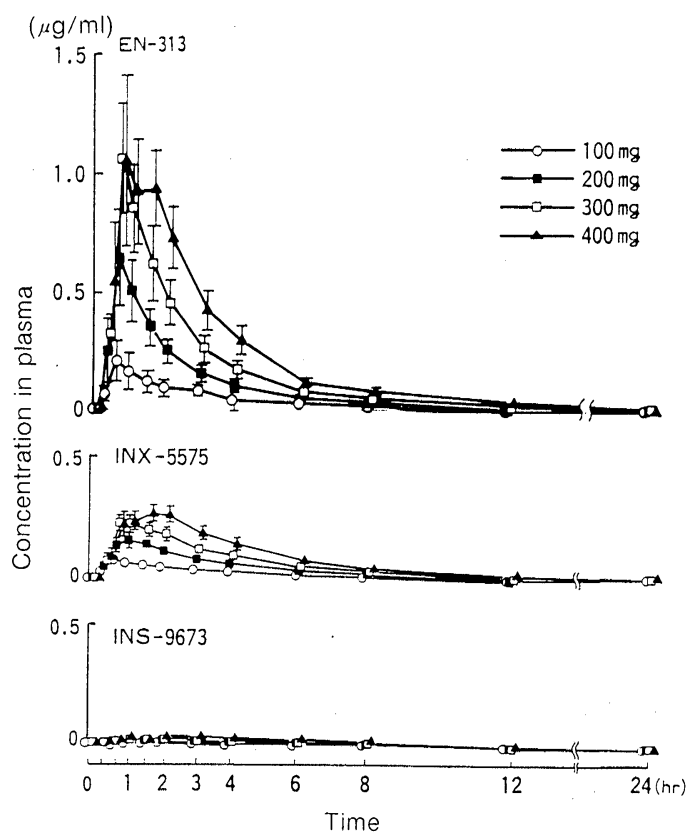

Mean \pm S.E. $(n=8)$

Fig. 5 Plasma concentration of EN-313, INX5575 and INS-9673 after different single oral doses of $\mathrm{EN}-313$
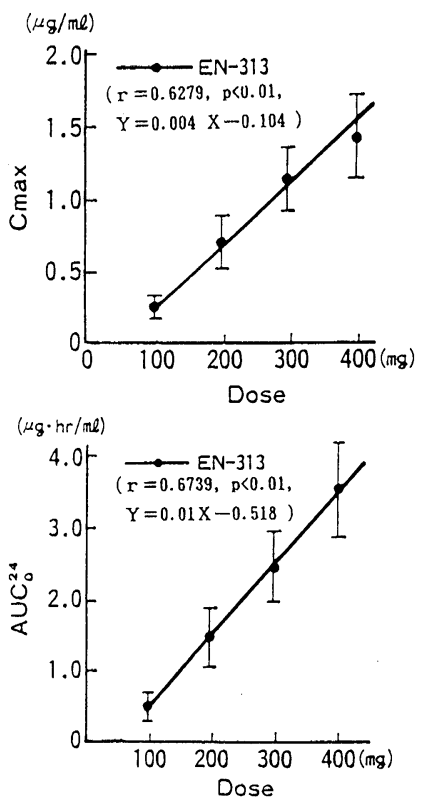

Mean \pm S.E. $(n=8)$

Fig. 6 Dose- $C_{\max }$ and dose-AUC relationships for EN-313 and INX-5575 after different single oral doses of $\mathrm{EN}-313$ 


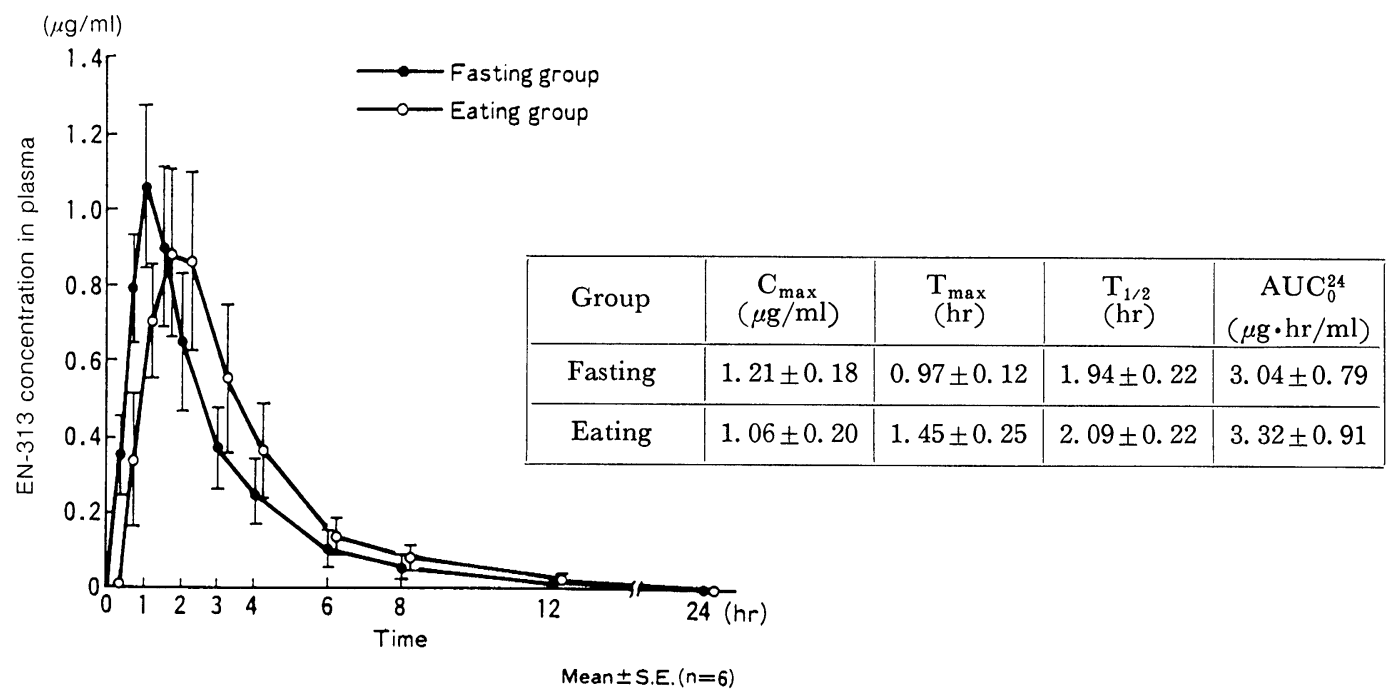

Fig. 7 Effect of meals on the EN-313 concentration in plasma after a single oral dose of EN-313

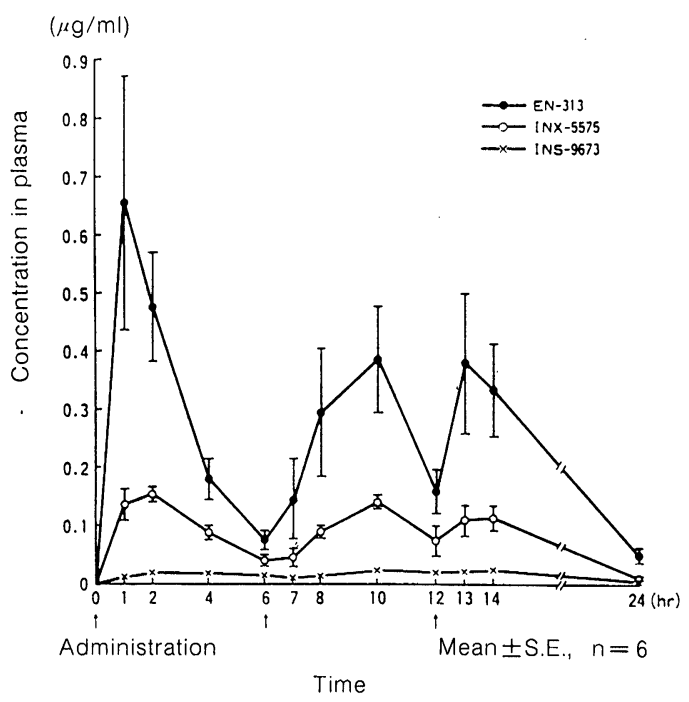

Fig. 8 Plasma concentration of EN-313, INX5575 and INS-9673 in the one-day test

In the seven-day test, the $\mathrm{C}_{\max }$ of $\mathrm{EN}-313$ was $0.465 \mu \mathrm{g} / \mathrm{ml}$ on day 1 , and was a similar level on day 4 , but on day 7 it decreased to $0.288 \mu \mathrm{g} / \mathrm{ml}$. The AUC of EN-313 was 1.48 $\mu \mathrm{g} \cdot \mathrm{hr} / \mathrm{ml}$ on day 1 and $1.519 \mu \mathrm{g} \cdot \mathrm{hr} / \mathrm{ml}$ on day 4 ; on day 7 it fell to $0.893 \mu \mathrm{g} \cdot \mathrm{hr} / \mathrm{ml}$, but the difference between day 1 and day 7 values was not statistically significant. $T_{\max }$ values for $\mathrm{EN}-$ 313 were $3.17,1.83$, and $3.67 \mathrm{hrs}$ on days 1 , 4 and 7 , respectively. The $\mathrm{C}_{\max }$ and $\mathrm{AUC}$ of INX-5575 were about $1 / 3$ those of $\mathrm{EN}-313$, as was found in the single-dose test. The plasma concentration of INS-9673 was even lower than that of INX-5575. No accumulation of EN-313 was seen over the 7-day oral administration (Fig. 9, Tab. 5).

The mean rates of excretion of the compounds in the urine were less than $1 \%$ (EN-313, $0.04 \%$; INX-5575, 0.51\%; INS-9673, 0.206 $\%$, even at a single dose of $400 \mathrm{mg}$. Percent excretion was thus in the order INX-5575>INS$9673>\mathrm{EN}-313$. There was no difference between two groups in the effect of meal test. In the oneday test, the proportion of INX-5575 excreted in the urine was $0.771 \%$, the highest level of the three compounds, and was followed by $0.121 \%$ of INS-9673. The urinary excretion of unchanged $\mathrm{EN}-313(0.037 \%)$ was lower than that of its two metabolites. The total excreted amount of all 3 compounds was less than $1 \%$. 
Tab. 4 Pharmacokinetic Parameters of EN-313 and INX-5575 in the One-Day Test

\begin{tabular}{c|c|c|c|c|c|c}
\hline & \multicolumn{3}{|c|}{ EN-313 } & \multicolumn{2}{c}{ INX-5575 } \\
\cline { 2 - 7 } & $1 \mathrm{st} *$ & $2 \mathrm{nd} *$ & $3 \mathrm{rd} * *$ & $1 \mathrm{st} *$ & 2nd* & 3rd** \\
\hline $\begin{array}{c}\mathrm{C}_{\max } \\
(\mu \mathrm{g} / \mathrm{ml})\end{array}$ & $0.728 \pm 0.195$ & $0.482 \pm 0.097$ & $0.421 \pm 0.101$ & $0.176 \pm 0.010$ & $0.153 \pm 0.009$ & $0.128 \pm 0.022$ \\
$\begin{array}{c}\mathrm{T}_{\max } \\
(\mathrm{hr})\end{array}$ & $1.50 \pm 0.22$ & $3.00 \pm 0.45$ & $1.50 \pm 0.22$ & $1.50 \pm 0.22$ & $3.33 \pm 0.42$ & $1.67 \pm 0.21$ \\
$\begin{array}{c}\mathrm{AUC} \\
(\mu \mathrm{g} \cdot \mathrm{hr} / \mathrm{ml})\end{array}$ & $1.804 \pm 0.400$ & $1.560 \pm 0.325$ & $2.552 \pm 0.542$ & $0.583 \pm 0.044$ & $0.555 \pm 0.055$ & $0.864 \pm 0.125$ \\
\hline
\end{tabular}

Mean \pm S.E., $n=6$, *The time of measurements are before, $(0), 1,2,4$ and 6 hours after the first and the second administration. **The time of measurements are $0,1,2$ and 12 hours after the third administration.

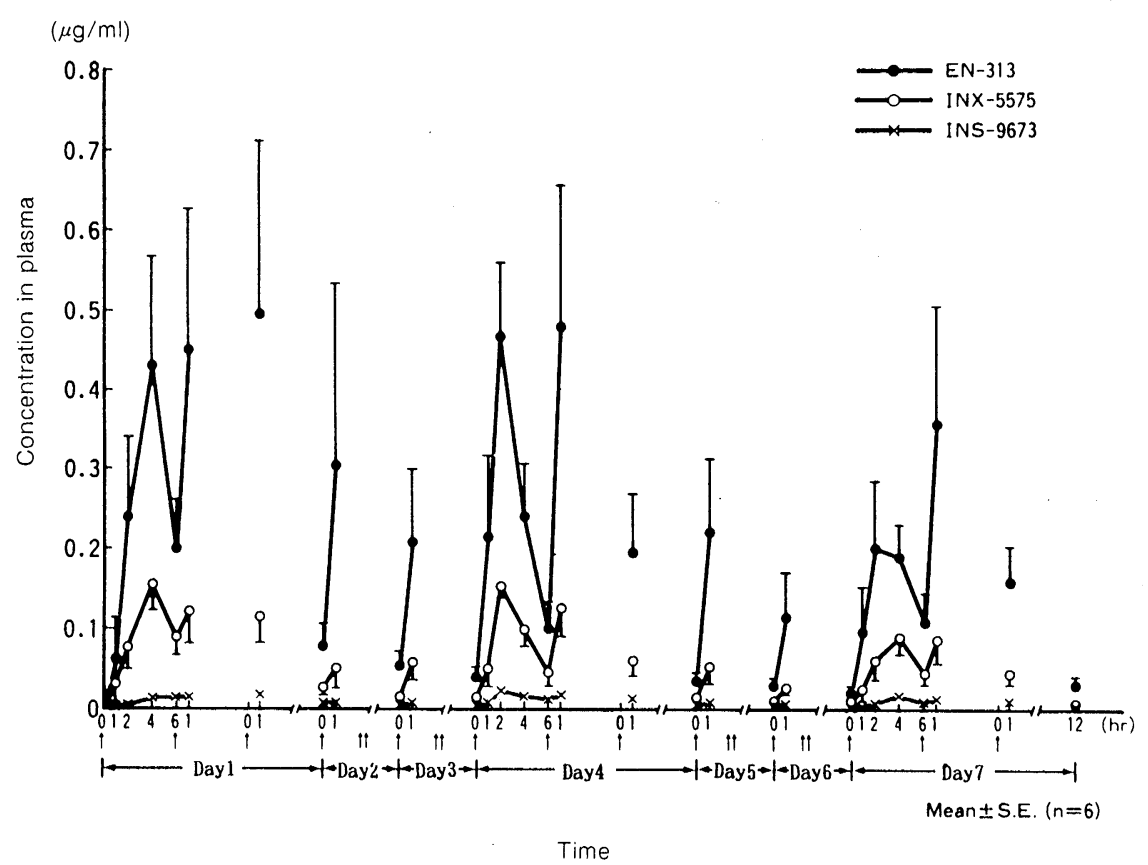

Fig. 9 Plasma concentration of EN-313, INX-5575 and INS-9673 in the seven-day test

Tab. 5 Pharmacokinetic Parameters of EN-313 and INX-5575 in the Seven-Day Test

\begin{tabular}{c|c|c|c|c|c|c}
\hline & \multicolumn{3}{|c|}{ EN-313 } & \multicolumn{3}{c}{ INX-5575 } \\
\cline { 2 - 7 } & Day 1 & Day 4 & Day 7 & Day 1 & Day 4 & Day 7 \\
\hline $\begin{array}{c}\mathrm{C}_{\max } \\
(\mu \mathrm{g} / \mathrm{ml}) \\
\begin{array}{c}\mathrm{T}_{\max } \\
(\mathrm{hr})\end{array}\end{array}$ & $0.465 \pm 0.122$ & $0.504 \pm 0.095$ & $0.288 \pm 0.055$ & $0.165 \pm 0.027$ & $0.160 \pm 0.012$ & $0.100 \pm 0.015$ \\
$\begin{array}{c}\mathrm{AUC}(-6 \\
(\mu \mathrm{g} \cdot \mathrm{hr} / \mathrm{ml})\end{array}$ & $1.480 \pm 0.429$ & $1.519 \pm 0.305$ & $0.893 \pm 0.218$ & $0.465 \pm 0.122$ & $0.504 \pm 0.095$ & $0.258 \pm 0.065$ \\
\hline
\end{tabular}

Mean \pm S.E., $n=6$ 
In the seven-day test, the mean value of EN313 was $0.02 \%$, the lowest of the three. INS9673 had the second lowest value of 0.113 , followed by $0.56 \%$ for INX-5575. This order of percentage excreted persisted throughout the test period.

\section{Discussion}

Many of the drugs having a main phenothiazine chain have an inhibiting activity on the central nervous system as exemplified by chlorpromazine, an $\mathrm{N}$-alkyl-phenothiazine derivative. In the case of EN-313, this inhibitory activity is weakened by the replacement of the alkyl group with an $\mathrm{N}$-acyl group at the $\mathrm{N}$ terminus of the phenothiazine chain. Its antiarrhythmic activity is enhanced by the carbamate side chain at the 2 position and by the lowering of the $\mathrm{pKa}$ value to 6.4 .

\section{1) Safety of EN-313}

US clinical trials have reported ${ }^{3,8,11}$ that the side effects caused by EN-313 include dizziness, nausea and headache. However, at the dosages (single dose, 100 400 $\mathrm{mg}$; repeat-dose, $300 \mathrm{mg}$ for 7 days) used in this phase I study, no specific subjective/objective symptom was observed. Further, blood pressure, body temperature and laboratory tests showed no abnormal changes attributable to EN-313.

An increase in pulse rate, a shortened $R R$ interval, and a prolonged $\mathrm{PQ}$ interval were observed from day 4. However, there was no significant change in QRS width, QTc, ST • T or $\mathrm{U}$ wave. The prolonged $\mathrm{PQ}$ interval seemed to reflect an effect of EN-313 on the atrioventricular node. It is presumed that the increase in pulse rate and the shortened $\mathrm{RR}$ interval were caused by secondary enhancement of the sympathetic nervous activity due to the negative inotropic action of the agent. However, there was no change in hemodynamic parameters as measured by echocardiogram. Since changes such as the shortened RR interval and the lengthened PQ interval occurred from day 4 of administration up to the time of test completion on day 7 , it was considered necessary in the clinical study to confirm the safety of $\mathrm{EN}-313$ in relation to any change found in the ECG within 1 week from the start of repeat-dose administration. According to clinical reports $3,4,13 \sim 15)$, an increase in QRS width has been noted in patients with ventricular tachycardia, which suggests that inhibition of intraventricular conduction may be more marked in patients with organic heart diseases such as myocardial infarction. The fact that EN-313 at the doses used in the present study caused no increase of QRS width or any change in QTc, but it did cause a lenghthened $P Q$ interval and a shortened RR interval suggests that the antiarrhythmic activity of low doses of EN-313 mainly affects the atrioventricular node.

2) Pharmacokinetics of EN-313

Earlier pharmacokinetic studies, 16,17) of EN313 have clarified the following points: (1) rapid absorption, (2) strong susceptibility to the first pass effect, (3) bioavailability of about $38 \%$, (4) $\mathrm{T}_{\max }$ of about $1 \mathrm{hr}$ and $\mathrm{a} \mathrm{T}_{1 / 2}$ of between 3 and $4 \mathrm{hrs}$ in healthy persons; (5) a distribution volume of about 11 liters $/ \mathrm{kg}$, and (6) plasma protein binding of approximately 95\%. A report by Howrie et al.17) using ${ }^{14} \mathrm{C}$-labelled drug showed that about $40 \%$ of orally administered EN-313 was excreted in the urine and about $60 \%$ in the feces, the latter probably via the bile.

In the single-dose study, the $\mathrm{C}_{\max }$ and $\mathrm{AUC}$ dose dependently increased, demonstrating the linear pharmacokinetics of $\mathrm{EN}-313$. The $\mathrm{C}_{\max }$ of EN-313 at the single-dose of $400 \mathrm{mg}$ was $1.412 \pm 0.284 \mu \mathrm{g} / \mathrm{ml}$. This value is nearly equal to that observed in healthy men in the US (1. $64 \pm 0.14 \mu \mathrm{g} / \mathrm{ml}, \mathrm{n}=9$ ).

The pharmacokinetic data of EN-313 however 
showed a tendency for the plasma concentrations of both unchanged EN-313 and its metabolites to fall when EN-313 was repeatedly administered. Woosely et al. ${ }^{18)}$ reported that repeated doses of $\mathrm{EN}-313$ given to 15 patients for 11 days led to declines of $\mathrm{C}_{\min }$ and $\mathrm{AUC}$ from the levels found on day 1 . They presumed that the repeated doses increased the clearance of EN-313 and decreased the plasma protein binding, thereby causing the induction of liver microsomal enzyme by the free $\mathrm{EN}-313$. Pieniaszek et al.19) noted that $\mathrm{EN}-313$ accelerates the clearance of antipyrine, and reported out the possibility of self-induction: A repeated administration of EN-313 enhances the activity of the metabolic enzyme system for this agent and thus promotes its own metabolism and excretion, lowering the concentration of EN-313 in the plasma.

The pharmacokinetics of INX-5575 and INS9673 were also studied, but their concentrations in plasma were lower than that of unchanged EN-313, as indicated by their AUCs, approximately $1 / 2$ and $1 / 10$ of that of $\mathrm{EN}-313$, respectively. The pharmacological activities of these metabolites were weaker than that of EN-313. It was considered, therefore, that the test results were not affected by the efficacy or by the toxicity of these metabolites. There was a small prolongation of $\mathrm{T}_{\max }$ when $\mathrm{EN}-313$ was administered after a meal. However, since the plasma concentration curve was similar to that observed in the fasting group, food probably had little effect on the pharmacokinetics of this agent.

Since EN-313 was metabolized almost completely, the amount excreted unchanged, together with the excreted amounts of the two major metabolites, in the urine was less than $1 \%$ of the respective oral dose.

The above results of pharmacokinetics of EN313, that is, linear pharmacokinetics in the single-dose study, $\mathrm{C}_{\max }$ decreased in the repeat- dose study, large inter-subject differences, the ratio of metabolites, the rate of urinary excretion and the effect of meal, were all similar to those found in the US traials. Therefore we concluded that there was no obvious racial differences in the pharmacokinetics of EN-313.

It has been reported that there is no decrease in the efficacy of EN-313 on administration of repeated doses, despite the reduction of its plasma concentration ${ }^{4,13)}$. Dorian et al.4) suggested that the existence of active metabolites demonstrates that the antiarrhythmic action of EN-313 lasts longer than its half life of $3 \sim 4 \mathrm{hrs}$, but they have not yet reported any detailed study of the concentration-efficacy relationship of this agent. We believe that it is necessary to conduct further studies including one to elucidate the efficacy mechanism.

\section{Conclusions}

In this phase I study of EN-313, the following results were obtained:

1) For the subjective symptoms, dizziness (at single-dose and repeat-dose studies) and nausea (at repeat-dose study) were found, but these were slight, and were regarded to have no relation to the test agent. There was no abnormal objective symptom throughout the test period.

2 ) In the single-dose study, there was no abnormal finding in blood pressure, pulse rate, body temperature, or the results of laboratory tests. In the seven-day test, a significant increase in pulse rate was observed from day 4 of administration.

3) In the single-dose study, there was no significant change in the ECG parameters or in the hemodynamic parameters obtained by echocardiogram. In the repeat-dose study, ECGs showed shortened RR and QT intervals and a prolonged PQ interval.

4) EN-313 is rapidly absorbed. It showed a 
linear pharmacokinetic behavior, the $\mathrm{C}_{\max }$ and AUC dose dependently increased. $T_{\max }$ was prolonged by $30 \mathrm{~min}$ when the drug was administered after a meal. Repeated-dose administration of $\mathrm{EN}-313$ lowered $\mathrm{C}_{\max }$ and $\mathrm{AUC}$ values below the level at the initial administration, suggesting that EN-313 had no accumulation tendency.

5 ) Excretion into the urine was a very small amount. The rate of excretion of both unchanged EN-313 and its principal active metabolites was less than $1 \%$.

The above results demonstrate the safety of EN -313 for clinical use, no problems having arisen during a 7-day period of repeat-dose administration.

\section{Acknowledgment}

We gratefully acknowledge Mrs. Tamiko Kikuchi and Mrs. Nobuko Yoshida for secretarial assistance.

\section{References}

1) Danilo, P., Langan, W.B., Rosen, M.R. et al.: Effects of the phenothiazine analog, EN-313, on ventricular arrhythmias in the dog. Eur. J. Pharmacol., 45: 127-139 (1977).

2) Chazov, E.I., Rosenshtraukh, L.V. and Shugushev, K.K.: Ethmozin. II. Effects of intravenous drug administration on atrioventricular nodal reentrant tachycardia. Am. Heart J., 108: 483-489 (1984).

3) Mann, D.E., Luck, J.C., Herre, J.M. et al.: Electrophysiologic effects of ethmozin in patients with ventricular tachycardia. Am. Heart J., 107: 674-679 (1984).

4) Dorian, P., Echt, D.S., Mead, R.H. et al.: Ethmozine: electrophysiology, hemodynamics, and antiarrhythmic efficacy in patients with life-threatening ventricular arrhythmias. Am. Heart J., 112: 327-333 (1986).

5) Kennedy, H.L., DeMaria, A.N., Sprague, M.K. et al.: Comparative efficacy of moricizine and quinidine for benign and potentially lethal ventricular arrhythmias. Am. J. Noninvas. Cardiol., 2: 98-105 (1988).

6) Morganroth, J., Orth, D.W., Michelson, E.L. et al.: Comparative antiarrhythmic efficacy and tolerance of ethmozin and quinidine (Abstract). Circulation, 58(Suppl. II): 103 (1978).

7) Butman, S.M., Knoll, M.L. and Gardin, J.M.:
Comparison of ethmozine to propranolol and the combination for ventricular arrhythmias. Am. J. Cardiol., 60: 603-607 (1987).

8) Pratt, C.M., Young, J.B., Francis, M. J. et al.: Comparative effect of disopyramide and ethmozine in suppressing complex ventricular arrhythmias by use of a double-blind placebocontrolled, longitudinal crossover design. Circulation 69: 288-297 (1984).

9) Wilmington, D.E.: ETHMOZINE (Moricizine $\mathrm{HCl}$ ) Investigational Brochure. E.I. du Pont de Nemours \& Co., Inc.: Sept. 15 (1987).

10) Podrid, P.J., Lyakishev, A., Lown, B. et al: Ethmozin, a new antiarrhythmic drug for suppressing ventricular premature complexes. Circulation, 61: 450-457 (1980).

11) Morganroth, J., Pearlman, A.S., Dunkman, W.B. et al.: Ethmozin: A new antiarrhythmic agent developed in the USSR. Efficacy and tolerance. Am. Heart J., 98: 621-628 (1979).

12) Whitney, C.C., Weinstein, S.H. and Gaylord, J.C.: High-performance liquid chromatographic determination of ethmozin in plasma. J. Pharm. Sci., 70: 462-463 (1981).

13) Salerno, D.M., Sharkey, P.J., Granrud, G.A. et al.: Efficacy, safety, hemodynamic effects, and pharmacokinetics of high-dose moricizine during short- and long-term therapy. Clin. Pharmacol.' Ther., 42: 201-209 (1987).

14) Miura, D.S., Wynn, J., Torres, V. et al: Antiarrhythmic efficacy of ethmozine in patients with ventricular tachycardia as determined by programmed electrical stimulation. Am. Heart J., 111: 661-666 (1986).

15) Singh, S.N., DiBianco, R., Gottidienr, J.S. et al.: Effect cf moricizine hydrochloride in reducing chronic high-frequency ventricular arrhythmia: Results of a prospective, controlled trial. Am. J. Cardiol., 53: 745-750 (1984).

16) Biollaz, J., Shaheen, O. and Wood, A.J.J.: Cimitidine inhibition of ethmozine metabolism. Clin. Pharmacol. Ther., 37: 665-668 (1985).

17) Howrie, D.L., Pieniaszek, H.J., Fogoros, R.N. et al: Disposition of moracizine (ethmoine) in healthy subjects after oral administration of radiolabelled drug. Eur. J. Clin. Pharmacol., 32: 607-610 (1987).

18) Woosly, R.L., Morganroth, J., Fogoros, R.N. et al.: Pharmacokinetics of moricizine $\mathrm{HCl}$. Am. J. Cardiol., 60: 35F-39F (1987).

19) Pieniaszek, H.J., Benedek, I.H. and Davidson, A.F.: Enzyme induction by moricizine: time course and extent in healthy voluteers (Abstract). J. Clin. Pharmacol., 29: 842 (1989). 